A LÓGICA CULTURAL URBANA:

Cultura de Massa e Indústria Cultural ${ }^{1}$

URBAN CULTURAL LOGIC:

High Culture and Cultural Industry;

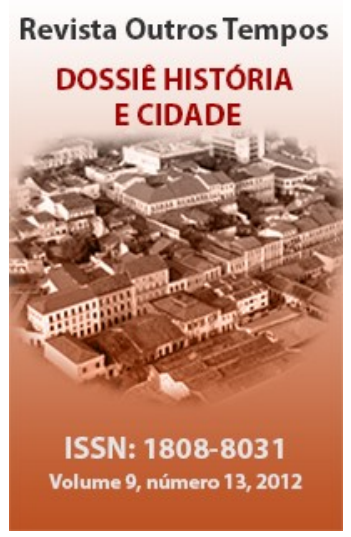

CARLOS GREGÓRIO DOS SANTOS GIANELLI

Mestrando PPGH - UDESC

Florianópolis, SC-Brasil

gianelli.87@hotmail.com

Resumo: Este artigo propõe uma discussão de alguns termos essenciais para se compreender a lógica cultural urbana. São eles: Cultura, Cultura Popular, Cultura de Massa e Indústria Cultural. Essa discussão possibilita partir para uma reflexão maior de como essa lógica se insere no silogismo urbano, esse por sua vez fundamental para a compreensão de diversos processos históricos envolvendo o desenvolvimento das cidades.

Palavras-chave: Cidade. Cultura. Indústria Cultural.

Abstract: This article proposes a discussion on some tag terms to understand the urban cultural logic such as: Culture, Popular Culture, Mass Culture and the Cultural Industry. This discussion allows a greater reflection from how this logic fits into the urban syllogism that in its turn is a key for the understanding of many historical processes involving the development of cities.

Keywords: City. Culture. Cultural Industry.

\footnotetext{
${ }^{1}$ Artigo submetido à avaliação em 30/03/2012 e aprovado para publicação em 09/05/2012.
} 
A cidade possui uma lógica cultural própria. Ela cria novas demandas que atendem a novas necessidades por ela mesma criadas. Ou seja, o produto que antes não precisava ser consumido ou produzido necessita de produção para atender a uma nova demanda que em breve será substituída por uma mais recente, e assim por diante. Para se iniciar uma reflexão sobre o tema, faz-se necessária a discussão de alguns termos. Aqui, em específico, serão: Cultura, Cultura Popular, Cultura de Massa e Indústria Cultural. Dentro desse último, teremos temas como a técnica, a ideologia, o sincretismo, a padronização, o conformismo, o lugar do folclore e, ainda, valores colocados dentro do debate como individualismo, juventude e amor. $\mathrm{Na}$ área de Cultura de Massa será abordada sua origem, conceituação, as escolas que a estudam (Frankfurt e a Escola Progressista Evolucionista), sua diferenciação com a "alta cultura" e, ainda, um esboço de um "método" de observação dessa massa.

\section{Cultura e Cultura Popular}

O que seria cultura? Esse termo que ao mesmo tempo possui uma imensa capacidade de abranger tudo o que existe numa sociedade, serve também para delimitar o que entra e o que fica de fora de sua conceituação. Uma concepção do termo torna-se missão cada vez mais difícil, visto que a Cultura tem como uma de suas principais características uma eterna metamorfose, tanto no interior de sua significação como no que se propõe a agregar ou excluir em sua área. Um conjunto de símbolos, tradições, adornos, indumentárias, palavras, idiomas, dialetos, canções, melodias, etc. seria o simples ajuntamento de todos esses elementos que constituiria a cultura? Teria ela uma função? Quando se diz que determinado povo "não tem cultura", ou que sujeito é "mais culto" que outro, o que se leva em consideração? Um povo sem cultura é uma folha em branco, sem nenhum símbolo, movimento ou nada que caracterize ou o diferencie de outro? E se essa tal folha em branco existir, ela por si não constituiria um elemento cultural? Dentro dessa discussão, o sociólogo francês Edgar Morin traz o seguinte:

[...] uma cultura constitui um corpo complexo de normas, símbolos, mitos e imagens que penetram o indivíduo em sua intimidade, estruturam os instintos, orientam as emoções. Esta penetração se efetua segundo trocas mentais de projeção e de identificação polarizadas nos símbolos, mitos e imagens da cultura como nas personalidades míticas ou reais que encarnam os valores (os ancestrais, os heróis, os deuses). Uma cultura fornece pontos de apoio imaginários à vida prática, pontos de apoio práticos à vida imaginária; ela alimenta o ser semi-real, semi-imaginário, que cada um secreta no interior de si (sua alma), o ser semi-real, semi-imaginário que cada um secreta no exterior de si e no qual se envolve (sua personalidade). (MORIN, 1975, p.10-11) 
Mais do que um simples recolhimento de símbolos, mitos e normas, Morin acrescenta para a discussão do termo a ideia dos pontos de apoio. A cultura não apenas fornece um conjunto de elementos que a constitui, mas oferece suporte para a criação de novas significações, inquietações ou, ainda, as ditas "trocas mentais de projeção e identificação." (Idem, ibidem, p. 10). O ser humano projeta no imaginário o que vive no real mitificando ou, ainda, modificando essas projeções com a finalidade de saciar uma vontade pendente na sua realidade. Da mesma maneira, o mítico acaba sendo projetado no real, completando essa via de mão dupla no momento em que são inseridos nos valores reais da sociedade aspectos vindos do imaginário.

A relação dialética entre o semi-imaginário e o semirreal norteará muitos dos principais aspectos relacionados à cultura popular. A cultura popular vem dessa relação de troca entre real e imaginário, tendo ainda outra relação de contraste presente para assim ser caracterizada diferente de outra cultura. Ela surge em diálogo ao saber culto dominante, “apresenta-se como ‘totalidade’ embora sendo, na verdade, construída, através da justaposição de elementos residuais e fragmentários [...] " (ARANTES, 1986, p. 18). Serão determinados teóricos que farão essa escolha e classificação dos saberes que devem ser colocados em alguma categoria diferente ou ainda que de alguma maneira não mereçam o mesmo lugar do "saber culto dominante.” (Idem, Ibidem, p.18). Feita essa classificação, as tradições nacionais são recriadas "segundo os moldes ditados pelas elites cultas, e com nova roupagem, desenvolvido, digerido e devolvido a todos os cidadãos.” (Idem, Ibidem, p.18). Nessa recriação, estarão imbricados diversos valores relacionados ao criador e seus objetivos em relação ao público consumidor dessa cultura popular. No momento em que se isola determinado aspecto cultural - seja uma festividade, uma dança, um rito qualquer-, esse primeiro momento de escolha já constitui parte do discurso da elite que o faz. Não se leva em conta o papel ou a relação daquele evento em específico com o conjunto de símbolos daquela sociedade (cidade, bairro, vilarejo) em questão. Isola-se o que parece soar mais interessante para um público, muitas vezes levando em conta a característica "curiosa" ou ainda "bizarra" que aquela tradição possui. Num exemplo hipotético, uma máscara de um monstro que auxilia no conto de alguma lenda presente no folclore de determinada região chama muito mais a atenção do que o simples vestido colorido das moças que fazem a dança. O monstro é isolado de todo o seu contexto apenas por conter em sua aparência uma isca para os olhos de algum curioso. Ele passa a ser o símbolo da cidade, sendo sua imagem disseminada nos mais diversos souvenirs turísticos. Feita essa escolha, ignora-se toda a significação daquele símbolo 
em relação a todo o conjunto de outros símbolos (menos bizarros ou curiosos), sendo ele por si próprio símbolo que enumera todo um folclore ou cultura popular local. Em cima dele ainda é feito um processo de recriação para que possa ser entendido e consumido por parte da população, possuindo uma significação totalmente abstrata e distante do original em serviço dessa nova função de "símbolo do folclore." Nesse ponto é que encontramos um paradoxo assinalado por Arantes no que diz respeito à criação de uma identidade nacional construída através desses símbolos "populares." Muitos desses símbolos são considerados populares por se tratarem de um símbolo "qualificado de ingênuo, de mau gosto indigesto, ineficaz, errado, anacrônico [...].” (Idem, Ibidem, p.13). Ou seja, os mesmos símbolos (danças, canções, festividades, celebrações) utilizados para exaltar a "identidade da nação como um todo" (Idem, Ibidem, p.15) são colocados como de menor significância cultural, sendo dado a eles o posto de popular.

Teve contato com muitos livros, professores experientes, simulações de cálculos, equipamentos precisos, antes de chegar na parte dita prática. Sua área, por isso, está relacionada ao "saber"; o engenheiro tem (em tese) uma bagagem de conhecimento enorme antes de mandar levantar o primeiro tijolo. Já o pedreiro, em alguns casos, mal sabe ler e escrever. Cursou cerca de cinco anos numa escola regular, e depois já teve contato com a profissão, começando como servente ajudando a carregar tijolos, preparar argamassa, limpar entulho, etc. Não teve contato com livros ou manuais relacionados à construção civil. Todo o seu conhecimento foi obtido de maneira prática através da sua convivência com pedreiros mais experientes que, no cotidiano da obra, foram ensinando o necessário para erguer uma casa. Para ele, na sociedade urbana, é reservado o lugar do "fazer". Apesar de que ele saber o que está fazendo, é visto apenas como aquele que executa um saber detido por outro "superior" (como o engenheiro, arquiteto, etc.) No campo cultural, essa separação entre o "saber" e o "fazer" ocorre de maneira semelhante. O músico erudito, paralelamente aos seus estudos regulares (em uma escola com as disciplinas tradicionais: português, matemática, geografia, história, etc.), cursa cerca de sete anos de aulas em algum conservatório musical, tendo as disciplinas de teoria musical, percepção musical, prática de instrumento e prática em conjunto (ensaios com alguma orquestra ou grupo musical). Após esse período, muitas vezes ingressa no curso superior, onde se dedicará por mais quatro anos no estudo específico de música. O músico erudito conhece os detalhes da parte técnica e de toda a significação dos diversos símbolos presentes na música. Sabe ler e interpretar partituras, construir arranjos elaborados, dissecar acordes complexos, construir campos harmônicos bem elaborados, tocar 
com velocidade e precisão cada nota descrita na pauta - enfim, torna-se, no campo da música, o detentor do "saber" musical. O músico popular muitas vezes não sabe ler partitura (existem algumas exceções). Faz sua música "de ouvido", sabendo o local das notas no seu determinado instrumento; decora algumas convenções (como posições dos dedos no braço de um violão para formar um acorde) e, através da prática, da repetição, consegue assimilar determinado estilo e se especializar em determinado instrumento. No entanto, ele não saberia, através da normatização padrão musical, expor o que faz. É muito raro, por exemplo, numa roda de samba, que o músico encarregado de tocar o pandeiro consiga colocar num pentagrama suas batidas repletas de quebras rítmicas, acentuações, dinâmicas, etc. Do mesmo jeito, o cantor não conseguiria dizer com precisão nota por nota do que canta, mas sabe o lugar de cada sílaba dentro da melodia, seja na hora de interpretar determinada canção ou até mesmo no momento em que compõe uma música nova. Sendo assim, cabe ao músico popular o lugar do "fazer" na área da música, sendo o seu conhecimento na área em muitas ocasiões estritamente prático.

Essa oposição de categorias entre o popular e o erudito radicada na diferenciação entre o "saber" e o "fazer" será uma das origens para a chamada "cultura popular". Outra corrente de ideias que se tem a respeito da cultura popular e a sua relação com a tradição é a de que a seleção de símbolos de determinado lugar ajudará sempre a traçar um panorama do passado daquele local. Como assinala Arantes:

Pensar a "cultura popular" como sinônimo de "tradição" é reafirmar constantemente a ideia de que a sua Idade de Ouro deu-se no passado. Em consequência disso, as sucessivas modificações por que necessariamente passaram esses objetos, concepções e práticas não podem ser compreendidas, senão como deturpadoras ou empobrecedoras. Aquilo que se considera como tendo tido vigência plena no passado só pode ser interpretado, no presente, como curiosidade. (Idem, Ibidem, p.17-18.)

Essa construção do "tradicional" é feita da mesma na maneira que a "cultura popular". Com a necessidade de fazer essa tradição, seja por algum momento histórico vivido pelo lugar como um pós-guerra, inserção de determinada localidade no mercado de turismo, exaltação de um país frente a uma crise econômica ou política, ou qualquer que seja o motivo, é feita uma seleção e justaposição de símbolos que darão origem às tais tradições. Para dar "credibilidade histórica" ou, ainda, cultural, esses símbolos são retirados da "cultura baixa", denominada então como popular. O que, na visão da elite, representa o povo, será eleito como tradição e, por consequência, como parte integrante da cultura popular. Essa nova roupagem é uma decisão totalmente arbitrária na medida em que com as modificações feitas, as tais "tradições" 
são devolvidas ao povo para serem consumidas de maneira indiscriminada. Acaba-se consumindo elementos culturais que vieram da sua rotina, do seu cotidiano, no entanto, tornam-se muito mais atraentes para o consumo após serem modificadas pelas elites cultas. Seria como se a receita do arroz e feijão tivesse sido selecionada como o principal símbolo gastronômico do local. E, depois disso, sofresse uma modificação em seus ingredientes com o acréscimo bizarro de um condimento como a canela em pó, depois disso voltando à comunidade, sendo apresentada ao povo em algum evento específico, ou sendo disseminada em jornais, filmes, novelas, etc., e passando a ser consumido como a "mais tradicional culinária" do local.

\section{Cultura de Massa}

Dessa relação entre "extração cultural local”, reafirmação e reprodução para o povo de maneira geral que se dá na cultura de massa, Waldenyr Caldas conceitua a Cultura de Massa da seguinte maneira:

[...] a Cultura de Massa consiste na produção industrial de um universo muito grande de produtos que abrange setores como a moda, o lazer no sentido mais amplo incluindo os esportes, o cinema, a imprensa escrita, falada e televisionada, os espetáculos públicos, a literatura, a música, enfim, um número muito grande de eventos e produtos que influenciam e caracterizam o atual estilo de vida do homem contemporâneo no meio urbano-industrial. (CALDAS, 1987, p. 16.)

Essa produção cultural em larga escala, como dito ali em ritmo industrial, tem diversas consequências estéticas e políticas para o produto criado. O uso da "cultura local" como "matéria prima cultural" é o primeiro passo para o processo de descaracterização apontado por Edgar Morin: “[...] a orientação consumidora destrói a autonomia e a hierarquia estética próprias da cultura cultivada. Na cultura de massa não há descontinuidade entre a arte e a vida." (MORIN, 1975, p. 13.). Dessa mistura, ou melhor, do uso da vida para a produção de alguma forma de arte, sendo no caso aqui uma produção cultural voltada ao lucro, um dos principais fenômenos que acabam por acontecer é o sincretismo. A mistura de valores totalmente dissipares a serviço de algum tipo de "resgate" de uma determinada cultura marca profundamente a cultura de massa. "Sincretismo é a palavra mais apta para traduzir a tendência a homogeneizar sob um denominador comum a diversidade dos conteúdos". (Idem, ibidem, p. 29.) Essa diversidade homogeneizante a serviço da diversidade é vista, por exemplo, a partir do momento em que o western estadunidense é mesclado à música caipira paulista em todos os campos estéticos cabíveis: nas letras da música, com temas envolvendo o 
maniqueísmo do bandido e ladrão; na estética indumentária das duplas, que passam a se vestir como caubóis; e, talvez, a mais sentida, que diz respeito ao arranjo das músicas, agora com trompetes e ponteios mariachis os quais marcam as questões locais de fronteira entre o México e o sul dos Estados Unidos, não havendo relação nenhuma com a cultura brasileira, paulista ou caipira. Essa apropriação estética servirá para maior propagação da música da dupla que adotar o conceito estético do caubói. Essa adoção se faz quase obrigatória no momento em que o artista está inserido na lógica do mercado capitalista da sociedade urbano-industrial: vender o produto que está sendo procurado para obter o maior lucro possível.

O sincretismo presente na cultura industrial não acontece apenas na mistura de valores culturais completamente distintos de localidades completamente diferentes (como visto no caso do western na música caipira), mas ele surge também na mistura de áreas de atuação diferentes. Ele "tende a unificar numa certa medida os dois setores da cultura industrial: o setor da informação e o setor do romanesco". (Idem, ibidem, p. 29). O que puder ser obtido em notícias que gerem curiosidade, que beirem o imaginário como acontecimentos bizarros, curiosidades sobre povoamentos isolados, crimes passionais, quebras de recordes de destreza ou força humana, animais nascidos com alguma mutação genética, acidentes automobilísticos dignos de Hollywood, todos esses tipos de acontecimentos, por fugirem do cotidiano comum, tornam-se excelentes "iscas" para a venda da informação mais tradicional, como acontecimentos políticos, boletins econômicos, informativos esportivos, etc. "A cultura de massa é animada por esse duplo movimento do imaginário arremedando o real e do real pegando as cores do imaginário.”(Idem, ibidem, p. 29.)

Dentre os estudos realizados sobre a cultura de massa e as suas diversas vertentes metodológicas, temos como destaque nas universidades duas escolas: a Escola de Frankfurt e a Escola Evolucionista - Progressista. São as mais estudadas e usadas em análises sobre o tema por possuírem posições fortemente radicais e, ao mesmo tempo, antagônicas entre si. Normalmente, faz-se um balanço filtrando o que cada corrente possa acrescentar para um debate mais amplo sobre o tema. A escolha de algum "lado" fica a critério do pesquisador que está fazendo seu trabalho. No entanto, conhecer bem as duas escolas e observar o que cada uma tem para contribuir com argumentos "pró" ou "contra" determinado assunto faz-se extremamente necessário para a construção de uma pesquisa mais sólida.

Por volta do ano de 1947 surgem as primeiras pesquisas marxistas relacionadas à Sociedade de Massa. O musicólogo e filósofo Theodor Wiesgrund Adorno dá inicio à relação da Escola de Frankfurt com o assunto. Com a finalidade de buscar um novo ponto de vista dos 
estudos culturais, Adorno ousa ao mudar o termo "Cultura de Massa" para "Indústria Cultural" (termo que será discutido adiante nesse artigo.) Para ele, a discussão sobre essa vertente dos estudos sobre produção cultural perdia o seu sentido quando a Cultura de Massa era confundida como sinônimo de Cultura Popular, sendo conceitos completamente diferentes entre si. O primeiro seria algo produzido com uma finalidade específica, para satisfazer o mercado, um público consumidor, e contribuir com toda a lógica do sistema e do mercado capitalista: produção em ritmo industrial, lei de oferta e procura, valorização do que estiver em alta, padronização, etc. Já o segundo seria uma produção espontânea de determinada comunidade ou localidade sem a intenção de ser vendida ou consumida, fazendo parte dos costumes, seja do cotidiano propriamente dito (uma canção de trabalho da lavoura) ou de alguma festividade religiosa. (CALDAS, 1987, p.33). De um modo geral, essa nova abordagem proposta por Adorno norteará as discussões propostas pela Escola de Frankfurt: ela "[...] não reconhece na sociedade de massa, a presença de um núcleo moral, um código de ética que respeite a vontade, os direitos e a autonomia do cidadão. [...] o consumidor é transformado num instrumento de lucro e dependente do capital." (Idem,ibidem, p. 41). Para citarmos mais alguns pensadores da Escola de Frankfurt, temos Erick Fromm, Hebert Marcuse, Walter Benjamin e Max Horkeheimer. (Idem, ibidem, p. 37) Em contrapartida, teóricos como Alan Swingewood, Edward Shils, Daniel Bell e L. Wirth possuem opiniões completamente diferentes sobre o fenômeno da Cultura de Massa. Esses, por sua vez, integram a chamada Escola Evolucionista - Progressista. De um modo geral, eles defendiam a ideia de que: “[...] a Cultura de Massa é, sobretudo, democrática e pluralista. A sociedade pós-industrial possibilitaria maior âmbito de iniciativa, liberdade e desenvolvimento do homem, através do surgimento da industrialização e da tecnologia.” (Idem, ibidem, p. 38) Dentro dessa perspectiva, a produção cultural seria feita de modo cada vez mais autônomo fazendo uso do aparato tecnológico de que a sociedade dispõe. A autonomia seria dada também por uma sociedade cada vez mais "plural", sendo esse pluralismo social (diversas classes sociais que interagem entre si), político (várias tendências político-ideológicas sendo respeitadas no processo de produção cultural) e, por consequência, uma pluralidade cultural que abrangeria os outros pluralismos citados. De acordo com o sociólogo estadunidense Daniel Bell, o sistema capitalista de consumo inserido na sociedade urbano-industrial não acabaria por criar uma Cultura de Massa homogênea tanto em conteúdo como em ideologia, mas havendo cada vez mais diversas vozes expressando-se de maneira livre e igual, ou, como os Evolucionistas - Progressistas preferem colocar, ter-se-ia um acesso "democrático" da produção cultural e de seus meios de divulgação. Essa democracia estaria ligada também à 
quebra de monopólio da alta cultura em relação ao povo, sendo que agora existe na Cultura de Massa uma produção de filmes, música, programas de televisão e rádio e literatura voltada a essa "classe baixa", que pode passar a consumir bens culturais e os compreender, benefício do qual antes só desfrutava a elite. Nesse contexto de pluralismo e acesso, as palavras de outro sociólogo estadunidense, L. Wirth, ajudam a retratar a posição Evolucionista-Progressista da Sociedade de Massa:

[...] um agregado de pessoas que participam, em muito maior grau, da vida e comum e compreendem pessoas cujas atitudes, sentimentos e opiniões têm alguma relação com as políticas estabelecidas por seus governos. Elas são uma entidade da época moderna, o produto da divisão do trabalho, das comunicações em massa e de um consenso conseguido mais ou menos democraticamente. (WIRTH, 1984 In CALDAS, 1987, p. 39)

Das escolas de pensamento relativas ao estudo da Cultura de Massa, como já dito anteriormente, não existirá uma correta. Até mesmo pelo fato de se colocarem em lados opostos, penso que as duas linhas acabam perdendo pontos interessantes a serem levados em conta. A "massificação" da cultura popular, com a sua extração e preparação para ser consumida em larga escala pela população, é inegável. Cada vez mais "símbolos nacionais" (ou locais) são escolhidos para serem disseminados como produto. Aqui, o termo Indústria Cultural apontado por Adorno, ou seja, a produção cultural obedecendo a ritmos e padrões da sociedade urbano-industrial como a produção em série, perda de qualidade, diminuição do valor estético, mostra-se cada vez mais forte e aperfeiçoada. Ainda na linha de Frankfurt, percebo uma produção cultural encabeçada por uma elite culta cada vez mais seleta, que escolhe e produz o que será consumido pelo povo em geral. Quando digo uma elite "culta", falo no sentido de um pequeno grupo determinante da cadeira produtiva cultural e não no sentido de ser um pequeno grupo detentor da alta cultura. Até porque essa elite culta acaba quase sempre optando por uma produção cultural em série, de cada vez menor qualidade, fornecendo a ilusão de que o povo está se informando ou adquirindo cultura. Isso acaba por gerar, agora sim, uma elite culta no sentido de que cada vez menos pessoas têm acesso a uma produção de qualidade que não é feita somente com a intenção de ser vendida ou consumida. Como aponta Harold L. Wilensky: "Os gostos comuns imprimem forma à cultura de massa; os padrões críticos sustentados por grupos produzindo autonomamente imprimem forma à alta cultura.” (WILINSKY, 1964 In COHN, 1978, p. 262)

Mas como poderíamos observar e analisar essa Sociedade de Massa, a qual "apresenta características como o isolamento, a perda da individualidade, a padronização, a atomização do indivíduo e uma cultura estandardizada cujo objetivo é agradar ao gosto médio de uma audiência indiferenciada?" (CALDAS, 1987, p. 30). Edgar Morin apresenta um método no 
qual o observador deve interagir com o que se propõe a analisar, não deve ficar isolado numa torre de marfim, deve vivenciar o que está disposto a estudar, seja acompanhando o noticiário comum, programas de televisão de comédia apelativa, programas de auditório, novelas com enredo previsível, discussões futebolísticas intermináveis sobre um determinado dérbi finalizado em 0 a 0 . Seria necessário acompanhar de perto a cultura de massa para assim tomar conhecimento de todo o seu movimento, dada a sua importância sócio-histórica tendo em vista que "A cultura de massa é, sem dúvida, a primeira cultura da história mundial a ser também plenamente estética. Isso significa que, apesar de seus mitos e seus engodos religiosos (como o culto a estrelas de cinema), é uma cultura fundamentalmente profana. [...]" (MORIN, 1975, p.67)

\section{Indústria Cultural}

O termo "Indústria Cultural" foi cunhado pelo musicólogo e filósofo Theodor Wiesgrund Adorno no ano de 1947, na publicação do livro Dialektik der Aufklärung, em pareceria com Max Horkeimer, em Amsterdã, (ADORNO, 1962 In COHN, 1978, p. 287), tendo assim iniciado os estudos marxistas sobre Cultura de Massa. Adorno traz esse novo termo para evitar uma confusão que se fazia ao misturar as expressões "Cultura de Massa" com "Cultura Popular", sendo dois temas completamente diferentes, o primeiro tratando de uma produção cultural em larga escala voltada ao consumo, e o segundo, uma "captação" da arte popular. O termo Indústria Cultural surgiria como perfeito substituto e esclarecedor no que diria respeito à “antiga” Cultura de Massa. (CALDAS, 1987, p. 33)

Além de trazer à tona os aspectos mais próximos a palavra "Indústria" (produção em série, padronização, etc.), Adorno mostra que a Indústria Cultural traz um prejuízo artístico enorme tanto para a cultura erudita quanto para a cultura popular: "A arte superior se vê frustrada de sua seriedade pela especulação sobre o efeito; a inferior perde, através de sua domesticação civilizadora [...]"(ADORNO, 1962 In COHN, 1978, p. 287) Antonio Augusto Arantes, no seu "O que é Cultura Popular", sintetiza de maneira interessante esse prejuízo causado à arte popular, ali colocada por Adorno como "inferior" (no sentido de que é feito "pelos de baixo", e não no sentido de menor qualidade):

A produção empresarial da arte "popular" - qualquer que seja a orientação ideológica e política de seus responsáveis - retira-lhe duas dimensões sociais fundamentais. Alterando data, local de apresentação e a própria organização do grupo artístico, ela transforma em produto terminal, evento isolado ou coisa, aquilo que, em seu contexto de ocorrência, é o ponto culminante de um processo que parte de um grupo social e a ele retorna, sendo indissociável da vida desse grupo. (ARANTES, 1986, p. 19-20) 
Essa transformação da arte "manufaturada" passando a ser "industrializada", tendo seus gestos, movimentos, canções, danças, etc., aperfeiçoadas no "nível técnico" (ARANTES, 1986, p. 20), age diretamente sobre todo o conjunto semiótico de determinada cultura a partir do momento em que essas representações artísticas são "domesticadas", agora, com a finalidade de serem apresentadas a um público consumidor.

Já o prejuízo causado em relação à arte erudita dará origem a outro termo estabelecido por Adorno e utilizado pelos estudiosos da Indústria Cultural: o kitsch. ${ }^{2}$ A partir do momento em que a uma obra erudita, tanto uma sinfonia de Beethoven como um quadro de Da Vinci, é adaptada ao consumo de massa, ela passa a ser kitsch. Essa categoria de produto da Indústria Cultural é facilmente observada na sociedade urbana. Usaremos de obras dos artistas citados anteriormente. Para a nona sinfonia de Beethoven poder ser consumida pelo grande público, ela teve que ser editada sumariamente. O tema que assoviamos e que aparece em brinquedos eletrônicos, toques de celular, que é utilizado em hinos religiosos, etc., é apenas um pequeno trecho de uma música bem maior. O prejuízo causado à obra original é colossal, tendo em vista que esse corte foi feito de forma totalmente arbitrária, sem o consentimento do autor. $\mathrm{E}$ sendo retirado, isolado um trecho, é ignorado todo o resto da melodia, harmonia e arranjo que a obra possui. Talvez, para Beethoven, a melodia escolhida pela Indústria não fosse a principal "mensagem" ou "sentimento" que ele queria demonstrar em sua produção musical. No momento de criação da obra, o compositor não teria a menor ideia de que aquela frase musical em específico fosse ganhar destaque, ou, mais que isso, fosse totalmente extraída da música completa para assim ser "digerida" com maior facilidade. Esse recorte feito em cima da composição de Ludwig Von Beethoven caracterizará o kitsch.

Outro exemplo bem conhecido é a reprodução em enorme quantidade feita do afresco A Última Ceia (em italiano L'Ultima Cena), de Leonardo da Vinci. Originalmente pintado na parede da igreja de Santa Maria delle Grazie, em Milão, o afresco feito para o protetor de da Vinci, o Duque Lodovico Sforza, tem seu sentido baseado principalmente na localidade em que se encontra. Fatores como a técnica utilizada, o afresco no qual é utilizado reboco, óleo e verniz, a luz do ambiente, o formato da parede, etc., também são completamente ignorados (como ocorrido com o "resto" da nona sinfonia de Beethoven). Isto para que, a partir de uma simples foto feita da pintura, ela possa ser reproduzida, vendida e colocada em quadros do mundo inteiro. Com o seu sentido fortemente, mas não exclusivamente, religioso (a descrição

\footnotetext{
${ }^{2}$ Do termo alemão verkitschen, que significa dar sentimento/sentimentalizar. Outra tradução, mais informal, para kitsch é "brega" ou ainda "bugiganga"._Tradução disponível em $<$ http://michaelis.uol.com.br/escolar/alemao/index.php? lingua $=$ alemao-portugues $\&$ palavra $=$ Kitsch $\& C P=352857 \&$ typeToSearchRadio $=$ exactly $>$ acesso no $\operatorname{dia} 18 / 06 / 2011$
} 
do momento retratado se encontra na Bíblia em João 13:21), a cópia da obra passa a enfeitar altares católicos em diversas moradias, capelas e paróquias. Pelo fato da obra retratar um momento de refeição - a ceia na qual Jesus revela que, dentre os doze apóstolos, alguém o trairia -, sua reprodução passa a enfeitar também diversas cozinhas, salas de jantar, refeitórios, restaurantes, etc. Nisso observa-se o consumo indiscriminado da obra de arte no momento em que ela passa a ser utilizada de enfeite religioso até um simples objeto de decoração. Isso sem contar as adaptações feitas em cima da obra com a inserção de materiais cintilantes em detalhes do quadro, luzes exaltando a "divindade" de Cristo, dentre outras anomalias estéticas. Tudo isso é kitsch: "um produto industrializado de qualidade inferior" (CALDAS, 1987, p. 34) em relação ao original.

Enquanto para as obras de arte a técnica presente diz respeito "à organização imanente da coisa, à sua lógica interna" (ADORNO, 1962 In COHN, 1978, p. 290), a técnica da Indústria Cultural é totalmente diferente, sendo essa relacionada à parte exterior da obra já finalizada. A técnica de determinada pintura utilizada num quadro pode ser "óleo sobre tela", pode ser uma gravura com grafite. Enfim, terá sido algo determinado pelo artista no momento de sua criação. Um compositor, ao escolher os timbres para sua música, o arranjo, a fim de determinar o momento exato em cada instrumento, participará da melodia; a harmonia que dará o tom ou, ainda, o clima da música, também integrarão sua técnica no seu momento de composição. Ou ainda, um poeta que na escolha do número de versos e rimas dita o ritmo da poesia, sendo ela um poema livre, um soneto, um haicai, enfim, será ele e mais ninguém que irá interferir na utilização da técnica combinando com algum anseio ou inspiração do artista. Já a técnica utilizada na Indústria Cultural encontra-se em outra esfera: ela será aplicada na obra já terminada e ao mesmo tempo influenciará nela, no seu consumo, na sua distribuição, sem a intenção de modificar sua forma intra-artística, porém, "sem respeitar a lei formal de autonomia estética." (Idem, Ibidem). Como visto no exemplo em relação ao uso da nona sinfonia de Beethoven, as notas musicais foram mantidas, os acordes foram mantidos, em alguns casos os timbres (instrumentos designados para cada voz do arranjo) foram respeitados. Mas, no momento em que se escolhe determinado trecho para ser reproduzido e vendido das mais diversas maneiras, essa interferência exterior acaba mudando completamente o núcleo da obra de arte, descaracterizando-a totalmente. Essa "caricatura" feita em cima da obra de arte, sendo feita através da aplicação da técnica criada pela Indústria Cultural, é apontada por Leo Lowenthal: “[...] um produto da cultura popular não tem nenhum traço de arte genuína, mas, em todos os seus meios de comunicação, a cultura popular prova ter suas próprias características genuínas: estandardização, estereotipia, conservantismo 
[...]"(LOWENTHAL, 1950 In COHN, 1978, p. 308) Uma das principais consequências de ação dessa técnica é o conformismo diante dos produtos estabelecidos pela Indústria Cultural:

\begin{abstract}
A ideia de que o mundo quer ser enganado tornou-se mais verdadeira do que, sem dúvida, jamais pretendeu ser. Não somente os homens caem no logro, como se diz, desde que isso the dê uma satisfação por mais fugaz que seja, como também desejam essa impostura que eles próprios entrevem; esforçam-se por fecharem os olhos e aprovam, numa espécie de auto-desprezo, aquilo que lhes ocorre e do qual sabem porque é fabricado. Sem o confessar, pressentem que suas vidas se thes tornam intoleráveis tão logo não mais se agarrem a satisfações que, na realidade, não o são. (ADORNO, 1962 In COHN, 1978, p. 290)
\end{abstract}

Outra característica forte presente na Indústria Cultural é a padronização, ou estandardização das produções culturais. Um dos fatores que levam a esse fator é a concentração técnico-burocrática dos meios de produção e comunicação. O conteúdo do jornal que será vendido na banca, o programa de rádio ou televisão que será transmitido, muitas vezes ao vivo, para todo o país, passa por diversos filtros que burocratizam e organizam toda essa informação. Essa manipulação será feita em relação aos "interesses anônimos", seja de uma linha de pensamento ou proposta ideológica do Estado, seja da relação da informação propagada com investidores, sejam eles patrocinadores diretos com propagandas de produtos ou acionistas da empresa, ou de outras demandas de prestação de contas necessárias para gerir o negócio. Por exemplo, se o Estado possui o interesse de que a população de uma maneira geral tome determinada vacina tendo em vista o acordo comercial feito com um grande laboratório, será cuidado para que se faça uma cobertura jornalística intensa da campanha de vacinação mostrando os postos de atendimento, médicos falando sobre o poder de cura da vacina (mostrando "credibilidade" à informação produzida), crianças vencendo o medo da agulha para se tornar mais saudáveis, etc. Se um dos principais patrocinadores da empresa for uma marca de refrigerante, serão evitadas reportagens que falem dos malefícios do consumo contínuo da bebida. Na reportagem sobre alimentação e vida saudável, as frituras, alimentos industrializados, falta de exercícios físicos serão lembrados, no entanto, o tal refrigerante será "omitido" da matéria. Nesse aspecto, a consequência direta sobre o que é produzido acaba sendo "a tendência a despersonalização da criação, à predominância da organização racional de produção (técnica, comercial, política) sobre a invenção, à desintegração do poder cultural.” (MORIN, 1975,p.19) Mas, como essa produção cultural tão padronizada em teoria, como estamos vendo aqui, é consumida como se fosse singular? Ou, ainda, como se servisse de maneira perfeita para cada pessoa que consome e não como algo padrão feito para todos? Esse "acabamento" feito em cima da produção vem de uma dose, muito controlada por sinal, de liberdade que é concedida para quem a faz: “[...] a Indústria Cultural precisa de um eletrodo negativo para funcionar positivamente. Esse 
eletrodo negativo vem a ser uma certa liberdade no seio de estruturas rígidas." (Idem, ibidem, p.23)

Quais ideologias estariam presentes na Indústria Cultural? A definição do termo "ideologia" dada pela filósofa e historiadora Marilena Chaui auxilia a elucidar tal questão: “[...] a ideologia consiste precisamente na transformação das ideias da classe dominante, em ideias dominantes para a sociedade como um todo, de modo que a classe que domina no plano material (econômico, social e político), também domina no plano espiritual (das ideias)." (CHAUI, 1981, p. 93-94) Gabriel Cohn segue na mesma linha de Chauí ao afirmar que "a ideologia corresponde ao conjunto de elementos imanentes à mensagem que dizem respeito aos seus significados conotativos." (COHN, 1978, p.339) Aqui fica evidente o sentido ou a função da ideologia presente na mensagem veiculada pela Indústria Cultural. $\mathrm{Na}$ definição trazida por Chaui, temos na "transformação das ideias da classe dominante" a produção ideológica feita pela "elite culta" (termo já discutido nesse artigo.) É uma minoria, formada por chefes de empresa, editores, redatores-chefes, membros da classe intelectual que demandará de forma completamente arbitrária as ideias, valores e costumes a serem consumidos pela imensa maioria: a classe trabalhadora da sociedade urbano-industrial.

Dentre os valores imbricados ideologicamente e propagados pela Indústria Cultural, um dos mais fortes talvez seja o individualismo. A maioria do que passa a ser vendido é para o bem do indivíduo, é para consumo imediato, não serve para dividir com ninguém. A satisfação pessoal com o produto, seja um aparelho eletrônico, um tônico capilar, um aparelho que promete deixar o seu corpo em forma com "apenas vinte minutos de uso diário", etc.tudo é feito em função da pessoa para o seu próprio bem estar. Cada vez mais os indivíduos se fecham como "propriedades privadas de si mesmo" ao comprar e consumir produtos dos quais se fazem necessário para a sua vida, necessidade essa dada pela mesma empresa ou veículo de comunicação da qual foi adquirido o produto. O individuo da sociedade moderna se vê numa roda viva de compra pela necessidade dada por quem quer vender, da qual se torna cada vez mais difícil escapar. "Esse individualismo é o herdeiro do individualismo pequeno-burguês, mas as determinações técnicas-industriais-capitalistas-consumidoras, como o dinamismo próprio da cultura de massa inocoluram-lhe aditivos, refizeram-no e vitaminaram-no"(MORIN, 1975, p.158)

Outro valor que vem à tona e é colocado como um dos principais norteadores da produção cultural de massa, ou da Indústria Cultural, é a juventude. O mundo ideal vendido pelos meios de comunicação, pelos programas de televisão, e presente em muitas letras de música, é de que a sociedade deve sempre ser jovem. Caso o indivíduo tenha ultrapassado 
essa efemeridade da juventude, ele deve de alguma maneira voltar a essa época. Os anos de experiência acumulados valem menos do que a novidade. Com o passar do tempo, você não se torna mais maduro, mais consciente, mas torna-se velho, obsoleto, ultrapassado. A juventude, e sua busca, vendida pela Indústria Cultural, vai de encontro ao que é ensinado nas famílias e escolas do "respeito ao mais velho." As tais "sabedorias antigas" cada vez valem menos na medida em que o novo conhecimento é o mais valorizado. A mensagem propagada é a "de que adianta saber de uma coisa que já passou? De que adianta saber de algo que já teve sua utilidade e agora não serve mais?" E nisso se vende a imagem de sociedade em eterna evolução, ou de que uma sociedade só evolui com a juventude, caso contrário fica estacionada no tempo. Ou, ainda, nas palavras de Morin:

Todo impulso juvenil corresponde a uma aceleração da história: porém, mais
amplamente, numa sociedade em rápida evolução, e sobretudo, numa civilização em
transformação acelerada como a nossa, o essencial não é mais a experiência
acumulada, mas a adesão ao movimento. A experiência dos velhos se torna
lengalenga desusada, anacronismo. A "sabedoria dos velhos" se transforma em
disparate. Não há mais sabedoria. (Idem, Ibidem, p. 132)

Cabe destacar como um dos valores vendidos pela Indústria Cultural o amor: "[...]o amor da cultura de massa busca seus conteúdos na vida e nas necessidades reais (individualismo moderno) e lhes fornece seus modelos.” (Idem, Ibidem, p. 120) O amor surge na sociedade urbano-industrial como a maior tradução possível de significação da felicidade. Um filme só é bem aceito na sociedade de massa quando tiver um final feliz. O "mocinho" e a "mocinha" do filme, ao se encontrarem no final da película, traduzirão em beijos, abraços e declarações de amor toda a felicidade cabível naquele momento para a vida dos dois. Nada é mais importante. O amor está acima de tudo e, por isso, se traduz como sinônimo de felicidade. Na música isso também se evidencia nas letras das canções. O amor passa a ser o principal tema das músicas mais vendidas, das primeiras nas "paradas de sucesso.” Inclusive, no que diz respeito à música sertaneja, essa será uma das principais mudanças sentidas na temática das canções. Para responder a uma necessidade mercadológica, os artistas da música sertaneja, muitos vindos da música caipira, mudarão os antigos temas de letras - como o trabalho na roça, os "causos" nas cidades do interior, a nova vida do campesino na cidade para brigas entre casais, desencontros amorosos, traições e diversos outros temas que tangem a temática do amor.

Fazendo-se valer desses valores, individualismo, juventude e amor, a Indústria Cultural constrói o que chamamos de mito. Esse mito, de acordo com Roland Barthes, "é um sistema de comunicação, é uma mensagem.” (BARTHES, 1957, In COHN, 1978, p.341) Seguindo ainda nessa linha, ele acrescenta que "o mito não poderia ser um objeto, um 
conceito ou uma idéia: é um modo de significação, é uma forma.”(Idem, ibidem.) Esses significados presentes no mito da sociedade de massa serão construídos das mais diversas maneiras. Esse termo que beira o imaginário, literalmente o mitológico, não é à toa, ao passo que os acontecimentos gerados pela Indústria Cultural serão sempre algo distante da nossa realidade, colocados quase sempre como histórias fantásticas presentes na vida real. Os atores dessas histórias são nomeados por Henry Raymond como "Olimpianos", (MORIN, 1975, p. 91-95) termo que Morin usará em seu "Cultura de Massas no Século XX." Esses seres do Olímpio Cultural seriam as estrelas de cinema, os cantores, escritores, diretores, que farão de suas vidas verdadeiras histórias mitológicas que sustentarão esse "imaginário-real" presente na Indústria Cultural. Os jornais, tanto escritos como televisionados, os tabloides, farão questão de mostrar, de modo majoritário, esse lado "mítico" da vida dos Olimpianos a fim de escrever uma biografia lendária para cada personagem. Esses artistas terão sua vida passada a limpo sempre à luz da aparência, facilitando assim a propagação e venda dos produtos a serem oferecidos para o consumo cultural de massa. Sem essa "isca" para o imaginário geral, o real ficaria muito óbvio, sem atrativo nenhum para o consumo. Se determinada pessoa canta bem, ela tem seus méritos, mas não será uma "estrela"; já se essa pessoa tem costumes excêntricos e envolve-se em episódios bizarros, ela chega perto do imaginário, habitando agora o Olimpio da Indústria Cultural. "Quanto mais completo o mundo como aparência, tanto mais inescrutável a aparência como ideologia.” (ADORNO, 1963, In COHN, 1978, p.347)

Uma das temáticas exploradas pela Indústria Cultural é a do folclore. No momento em que determinada festividade é "extraída" do seu habitat natural e passa a ser comercializada, o folclore entra no sistema industrial de propagação cultural. Várias danças, ritos, festividades, presentes na Cultura Popular, a partir do instante em que se vê a possibilidade do uso comercial dela, passarão a ser normatizados, perdendo muito do seu significado original. Morin fala dessa mudança da relação entre a mudança da festa popular para o espetáculo:

[...] a "festa", momento supremo da cultura folclórica, na qual todos participam do jogo e do rito, tende a desaparecer em benefício do espetáculo.Ao homem da festa sucede o que chamamos de "público", "audiência", "espectadores". O elo imediato e concreto se torna uma teleparticipação mental. (MORIN, 1975, p. 52)

A dança que era feita entre os moradores de uma localidade, como na festa do Divino, por exemplo, agora é enquadrada no formato de apresentação. Esse formato consiste em uma rotina de ensaios, em movimentos combinados, em "agradar" determinado público em algum evento, na preocupação de melhorar o "nível técnico" no acerto de ritmos, vocais e afinações, etc. As danças e cantos configuravam um momento de interação na comunidade, na qual não existia um julgamento de uma apresentação "boa" ou "ruim". Era uma festa meio religiosa 
meio profana, mas que não tinha essa demanda de beleza "plástica" que uma apresentação dita "tipicamente folclórica" tem. O caráter de espontaneidade, traço marcante da cultura popular, se perde no momento em que ela será feita para o consumo, para a apreciação pontual.

É na apropriação, tanto de valores (juventude, amor, individualismo, etc.) como de temáticas (folclore) pertinentes à vida na sociedade urbana capitalista, que a Indústria Cultural erguerá seus alicerces. Todo o "bem cultural" produzido passa ser "bem material" com a finalidade de consumo, de venda, da alimentação de um mercado que a cada dia busca novos campos de atuação. "Toda a práxis da indústria cultural transfere, sem mais, a motivação do lucro às criações espirituais.”(ADORNO, 1963, In COHN, 1978, p.288) 


\section{REFERÊNCIAS BIBLIOGRÁFICAS}

ARANTES, Antonio Augusto. O que é cultura popular. 11. ed. São Paulo (SP):

CALDAS, Waldenyr. O que todo cidadão precisa saber sobre a cultura de massa política de comunicações. São Paulo: Global, 1987

CHAUI, Marilena. O que é ideologia. 4ª ed. São Paulo: Brasiliense, 1981.

COHN, Gabriel. . Comunicação e indústria cultural. São Paulo (SP): Companhia Editora Nacional, 1978

MORIN, Edgar. Cultura de massas no século XX : o espírito de tempo. 3. ed. Rio de Janeiro: Forense - Universitária, 1975. 